\title{
Contribuições de Design Thinking à humanização do tratamento de câncer infantil
}

\author{
Design Thinking contributions for the humanization of childhood cancer care
}

\author{
BELLUCCI, Miguel; Tecnólogo em Design Gráfico; \\ Centro Universitário Eurípides de Marília \\ miguel_bellucci@yahoo.com.br \\ MARTINS, Rosane; Doutora em Engenharia de Produção; \\ Universidade Estadual de Londrina \\ rosane@uel.br
}

\begin{abstract}
RESUMO
A proposta deste artigo foi de investigar a situação do atendimento a crianças com câncer com o objetivo de apontar quais as contribuições que o design thinking pode oferecer para a humanização do tratamento dessa doença exemplificando casos que obtiveram resultados satisfatórios com esse novo modelo de gestão. Através de pesquisa qualitativa, por meio de entrevistas e etnografia, foi possível identificar algumas oportunidades de intervenção.
\end{abstract}

Palavras Chave: Design Thinking; Câncer infantil ; Humanização.

\begin{abstract}
The purpose of this article was to investigate the situation of care for children with cancer in order to point out what the contributions that design thinking can provide for the humane treatment of this disease exemplifying cases that had satisfactory results through this new management model. Through qualitative research, through interviews and ethnography, it was possible to identify some opportunities for intervention.
\end{abstract}

Keywords: Design Thinking; Childhood cancer; Humanization.

\section{INTRODUÇÃO}

\subsection{Apresentação do Tema}

Apesar de ser um problema muito discutido atualmente, o câncer ainda é tratado com muito pessimismo perante a sociedade. Nem todos estão preparados para receber uma notícia tão impactante pela qual se caracteriza o diagnóstico de um câncer e, quando uma criança, considerado um ser humano frágil e indefeso, recebe tal diagnóstico, a reação pode ser ainda mais traumatizante para o paciente e principalmente para a família.

De acordo com dados apontados pelo Instituto Nacional do Câncer (INCA), as chances de cura aumentaram ao longo das últimas décadas. Apesar de a doença ser a segunda causa de mortalidade proporcional entre crianças e adolescentes brasileiros de 1 a 19 anos de idade, estima-se que em $70 \%$ a $80 \%$ dos casos de crianças acometidas de câncer podem ser curados. A expectativa de vida de crianças com câncer só não é maior do que as mulheres com câncer 
de mama.

Ainda segundo o INCA, quando se tenta interpretar as tendências das taxas relativas aos tumores na infância, depara-se com duas principais dificuldades: Primeira, a raridade da ocorrência do câncer nesta fase da vida, e, segunda, a utilização de modelos de tratamento mais aplicáveis ao câncer de adultos, o que pode ocasionar diagnósticos imprecisos, pois, crianças e jovens necessitam de um cuidado específico. Portanto, informar a população sobre a importância da prevenção de câncer na infância é primordial para a obtenção de sucesso no aumento dos índices de cura da doença. Alguns fatores que dificultam o diagnóstico são: a desinformação dos pais, o medo do diagnóstico de câncer (que podem levar à negação dos sintomas) e a desinformação dos médicos.

Mesmo que os dados do INCA apontem que o tratamento oncológico evoluiu e atingiu níveis satisfatórios de cura, muitas vezes o processo não é tratado com a importância que deveria. Fatores como a humanização e a satisfação dos pacientes e cuidadores são esquecidos ou deixados de lado. E também existe o fato de que muitos médicos não são preparados para se comunicar efetivamente com a família e o paciente, o que acaba agravando o quadro de ansiedade. Muitos cuidadores reclamam a respeito da falta de diálogo existente entre eles e o médico. Por mais que exista esse diálogo, o mesmo não alcança a compreensão dos familiares.

Deve-se entender que a cura não deve se basear somente na recuperação biológica, mas também no bem-estar e na qualidade de vida da criança. Tão importante quanto o tratamento em si, é a atenção dada aos aspectos sociais da doença.

O trabalho multidisciplinar coordenado por especialistas como médicos, enfermeiros, psicólogos, pedagogos, assistentes sociais, entre outros, é determinante para o êxito do tratamento. Porém, partir somente desta premissa não é o suficiente, pois em um grupo multidisciplinar, cada indivíduo defende sua própria especialidade técnica, fazendo com que os riscos de ineficácia sejam maiores. Por isso há uma necessidade em transformar esta em uma atividade interdisciplinar, a qual todos estejam em sintonia, agindo de forma recíproca para que haja enriquecimento mútuo. A interdisciplinaridade possibilita diversos olhares sobre a mesma questão através de uma visão integradora entre as disciplinas a fim de esclarecer e solucionar novos problemas.

Abordagens inovadoras, como a do design thinking, podem trazer excelentes benefícios para todos os atores envolvidos nesse contexto, tais como profissionais da saúde, cuidadores, família, paciente, entre outros. Além de ser uma atividade interdisciplinar centrada no usuário, o design thinking propicia uma cultura de inovação, estimula a empatia e a utilização do conhecimento para criar oportunidades, projetar experiências, testar protótipos (podendo ser formas de comunicação, novos produtos, serviços, sistemas, tecnologias, etc) e avaliar resultados através de feedback e acompanhamento. Para que isso ocorra, as pessoas envolvidas no processo devem lançar mão de conceitos como envolvimento, colaboração, participação ativa e, acima de tudo, engajamento.

A ideia é que, à medida que o design thinking começa a sair do estúdio e se disseminar pela empresa, pelo setor de serviços e pela esfera pública, pode nos ajudar a solucionar uma variedade maior de problemas. O design pode nos ajudar a melhorar nossa vida agora. $O$ design thinking pode nos ajudar a traçar um caminho para o futuro. (BROWN, 2009, p.139)

Com isso, a necessidade de melhorar a situação do tratamento de câncer infantil pode servir como oportunidade para estimular novos comportamentos, novas soluções, novas maneiras de pensar perante o sistema de oncologia infantil considerando todos os atores que 
compõem o mesmo.

\subsection{Problema}

Com base nos dados apresentados acima foi elaborada a pergunta que norteará este artigo: Como a abordagem do design thinking pode contribuir para a melhoria e humanização da jornada de uma criança com câncer?

\subsection{Objetivos}

\subsubsection{Objetivo Geral}

Apontar quais contribuições que a estratégia focada no usuário caracterizada pelo design thinking oferece para a humanização do tratamento de câncer e como isso pode ser revertido especificamente para a melhoria do tratamento de câncer infantil.

\subsubsection{Objetivos Específicos}

- Entender como funciona atualmente o tratamento de câncer infantil em Londrina-PR e como os profissionais inseridos nesse contexto se relacionam com colegas de trabalho e principalmente com o paciente e seus familiares.

- Relacionar o sistema de produção e decodificação do conhecimento com as habilidades do design thinker.

- Exemplificar casos que obtiveram sucesso utilizando métodos de design thinking na área da saúde, dando prioridade aos que trabalham no combate ao câncer.

- Identificar oportunidades para melhorias, detectando os problemas recorrentes no setor de oncologia infantil através de pesquisa etnográfica e entrevistas para, em seguida, propor diretrizes para possíveis intervenções.

\subsection{Justificativa}

Apesar do avanço da medicina, da evolução tecnológica, do desenvolvimento de novas técnicas médicas e do progresso dos índices de cura biológica do câncer, a ótica dos profissionais sobre as questões sociais e humanitárias é bastante ofuscada.

Não se pode culpar somente os médicos e enfermeiros pela falta de cuidado a esses aspectos, pois os mesmos dependem de várias condições estruturais e organizacionais favoráveis para que possam realizar seu trabalho de forma plena e, de acordo com as informações transmitidas diariamente pelos veículos de comunicação, os recursos destinados para a área da saúde no Brasil são mal distribuídos. A cada ano são divulgadas diversas notícias de casos em que parte da verba que seria destinada à construção e manutenção de hospitais fora desviada. Isso acaba gerando um quadro ainda maior de indignação e revolta por parte da população, frustração por parte dos profissionais, além de atingir diretamente os pacientes, que acabam sofrendo com a decadência dos cuidados como atendimento, tratamento e recuperação.

Infelizmente é muito difícil controlar essas variáveis devido ao descomprometimento das autoridades, o que acaba tornando a população impotente perante tal situação. Apesar das limitações do sistema, atualmente existem grandes iniciativas (privadas, filantrópicas, comunitárias) que comprovam que, se houver atitude comunitária em um ambiente que haja respeito, responsabilidade, compartilhando de ideias e perseverança nos esforços a fim de promover o bem-estar da população, tal quadro com certeza será revertido.

Por isso, é fundamental entender como funciona o tratamento de câncer nos hospitais, pois, somente tendo conhecimento da realidade dos envolvidos neste processo que se pode propor a mudança de pensamento através de novas práticas, novos comportamentos.

Hoje existe um espaço em que há condições favoráveis para o incentivo à humanização. No mundo globalizado, com o avanço da comunicação, principalmente com o surgimento da internet, as 
grandes mobilizações ganharam muita força.

Segundo Morace (2009), "a capacidade de combinações típicas do "corta e cola" criativo, a velocidade relacional do SMS, a memória seletiva do iPod, entre outras formas de "faça você mesmo", colocam a sociedade, cada vez mais, rumo ao consumo autoral". Essa nova abordagem que busca um novo sentido de inovação unindo a criatividade ao conforto é denominada Terceiro Renascimento.

Hoje em dia existe uma grande preocupação também com o bem-estar da sociedade. A opinião pública está cada vez mais apoiada no argumento do desenvolvimento sustentável, dando bastante importância para as causas sociais e ambientais.

Fazer parte de uma experiência humanitária é muito gratificante. Serve como um processo de renovação profissional, social e até mesmo espiritual. Quando alguém está engajado em fornecer ajuda ao próximo, está também disposto a dedicar parte de seu tempo precioso para amenizar a realidade sofrida das pessoas. Isso acaba estimulando também a empatia, pois é compreendendo a dor e o sofrimento do paciente que se podem tomar as decisões corretas visando sua recuperação, seja biológica, psicológica ou social. Ou seja, essa iniciativa não se sustenta apenas em oferecer apoio moral, mas sim como uma maneira de entender as necessidades dessas pessoas "se colocando no lugar delas".

Torna-se essencial então a sensibilização da sociedade quanto à necessidade de se adotar novas medidas, novas perspectivas em relação ao controle dos tratamentos de câncer no país. Com isso, é possível incentivar novas pesquisas nesta área, a fim de motivar equipes multidisciplinares a aderirem o modelo de gestão idealizada pelo design thinking em seus processos, e também inspirar novas gerações de profissionais educando-os sobre a importância que este artigo aborda.

O design tem a capacidade de promover a inovação rumo à sustentabilidade. Para ser um design thinker, a pessoa não precisa ser necessariamente um designer.

O design tem o poder de enriquecer nossa vida envolvendo nossas emoções por meio de imagens, formas, texturas, cores, sons e aromas. A natureza intrinsecamente centrada no ser humano do design thinking aponta para o próximo passo: podemos utilizar nossa empatia e conhecimento das pessoas para projetar experiências que criem oportunidades para o envolvimento e a participação ativa. (BROWN, 2009, p.109)

Esse trabalho tem como objetivo mostrar uma atuação eficaz do design thinking, exemplificando casos que obtiveram resultados satisfatórios por meio desta nova maneira de pensar e, baseado nessa demonstração e sustentado pela fundamentação teórica, propor diretrizes para solucionar problemas recorrentes nos setores de oncologia infantil dos hospitais brasileiros.

\section{FUNDAMENTAÇÃO TEÓRICA}

\subsection{Gestão do Conhecimento}

\subsubsection{A diferença entre dados, informações e os diferentes tipos de conhecimento}

O conhecimento, introduzido por Platão e citado por Nonaka e Takeuchi (1997), é definido como uma "crença verdadeiramente justificada", pois são justificadas a partir de conhecimentos evidentes, portanto, verdadeiros.

Para Davenport e Prusak, dados configuram um conjunto de conceitos, fatos distintos e objetivos relacionados a eventos, armazenados em sistemas, tecnológicos ou não. Já informação é uma mensagem, portanto, possui um emitente e um receptor, tem por finalidade mudar o modo como o destinatário vê algo, que exercerá algum impacto sobre seu julgamento e comportamento. E por fim, conhecimento é uma mistura fluida de experiência condensada, valores, informação contextual e insight experimentado, a qual proporciona uma estrutura para a avaliação e incorporação de novas experiências e informações. 
Existem cinco tipos de conhecimento, sendo eles: explícito, tácito, cultural, subjetivo e objetivo. Segundo Nonaka e Takeuchi (1997), conhecimento explícito é "articulado na linguagem formal, inclusive em afirmações gramaticais, expressões matemáticas, especificações, manuais e assim por diante", e conhecimento tácito é "o conhecimento pessoal incorporado à experiência individual e envolve fatores intangíveis como, por exemplo, crenças pessoais, perspectivas e sistemas de valores". O conhecimento tácito é difícil de ser articulado na linguagem formal. O conhecimento cultural segundo Choo (2003) "não é codificado, mas divulgado amplamente ao longo de vínculos e relacionamentos que ligam um grupo" sendo este expresso em normas e crenças compartilhadas. Já o conhecimento subjetivo segundo Popper (1975), é o conhecimento que nasce com o indivíduo. Para o autor "não existe conhecimento subjetivo puro ou genuíno, ou não adulterado". De acordo com McElroy (2003), este conhecimento pode tomar a forma de crenças e predisposição a crenças embutidas na mente de agentes que podem ser indivíduos, times, grupos, comunidades, etc. E por fim, o conhecimento objetivo de acordo com McElroy (2003), o conhecimento objetivo é uma forma de expressão linguística expressa em artefatos, assim, os artefatos explicitam o conhecimento subjetivo dos agentes.

\subsubsection{A evolução da Gestão do Conhecimento em três gerações}

A Gestão do Conhecimento é dividida cronologicamente em três gerações: a primeira geração, citada por Snowden (apud FIRESTONE e McELROY, 2003); a segunda geração, caracterizada pelo modelo SECI de Nonaka e Takeuchi; e a nova gestão do conhecimento de Firestone e McElroy.

A primeira geração, dirigido pela tecnologia da informação, prioriza a distribuição das informações para tomadores de decisões. Esta teoria foca somente no compartilhamento e integração do conhecimento ou lado fornecedor do conhecimento. Portanto, esta está subordinada à estratégia e suportada por ela.

A segunda geração descreve a conversão do conhecimento por meio do uso dos conhecimentos explícito e tácito. As combinações desses conhecimentos geram quatro modelos de conversão denominados como socialização, externalização combinação e internalização. Essa conversão, criada por Nonaka e Takeuchi (1997) e denominada "modelo SECl", centra-se na criação do conhecimento, ou produção do conhecimento.

Nesta teoria os autores definem como socialização um processo de compartilhamento de experiências. É o aprendizado entre mestre e aprendiz por meio da observação, imitação e prática. Já a externalização é um processo de articulação dos conhecimentos normalmente orientada pela metáfora e/ou analogia. Por sua vez, a combinação é um processo de sistematização de conceitos explícitos em um sistema de conhecimento. E por fim, a internalização é o processo de incorporação do conhecimento explícito no conhecimento tácito através da verbalização e a diagramação do conhecimento em forma de documentos, manuais ou histórias orais.

E por fim, a nova era da gestão do conhecimento de Firestone e McElroy $(2003$, p.70) "é uma disciplina de gestão que visa melhorar o processamento do conhecimento organizacional". Nesta teoria, a Gestão do Conhecimento se reduz a Processo de Gestão do Conhecimento que segundo os autores é: "uma interação em curso, persistente, proposital entre agentes humanos, por meio da qual os agentes participantes gerenciam outros agentes, componentes, e as atividades participantes no processo do conhecimento básico". Esse modelo, como um processo, visa o gerenciamento dos processos de conhecimento e seus resultados.

Diferentemente do modelo $\mathrm{SECl}$ que utiliza dois modos de conversão do conhecimento, a Nova Gestão do Conhecimento relaciona cinco tipos de conhecimento, sendo eles explícito, tácito, cultural, subjetivo e objetivo. Isso gera não só quatro, mas vinte e cinco conversões de conhecimento.

Choo (2003) cita três processos de produção do conhecimento. O primeiro é o processo de conhecimento organizacional, o segundo é denominado atividades de construção do conhecimento, e por fim, o terceiro é nomeado construção do conhecimento.

Dos três processos, o qual se assemelha mais com as habilidades do design thinker é o processo de atividades de construção do conhecimento. Neste, identificam-se quatro atividades realizadas no desenvolvimento de novos produtos e nos processos por meio dos quais a organização produz conhecimento: solução criativa e compartilhamento dos problemas, implementação e integração de 
novas metodologias e ferramentas, experimentação e prototipagem e, importação do conhecimento.

\subsection{Design thinking: uma abordagem inovadora centrada no ser humano}

De acordo com Martin, o design thinking "promove o equilíbrio entre o pensamento analítico e o intuitivo. É forma de pensamento que possibilita o movimento através do funil do conhecimento" (MARTIN, 2009, p.6).

Em contrapartida com as metodologias tradicionais, Brown $(2009$, p.16) afirma que

não existe uma "melhor forma" de percorrer o processo ... o continuum da inovação pode ser visto mais com um sistema de espaços que se sobrepõem do que uma sequência de passo ordenados. Podemos pensar neles como a inspiração, o problema ou oportunidade que motiva a busca por soluções; a idealização, o processo de gerar, desenvolver e testar idéias; e a implementação, o caminho que vai do estúdio de design ao mercado. (BROWN, 2009, pg. 16)

Ainda segundo o autor, estes espaços ocorrem em dois tipos de pensamentos: o pensamento divergente que, "consiste em multiplicar as opões para criar escolhas"; e o convergente cujo "é uma forma prática de decidir alternativas existentes". Enquanto o pensamento divergente multiplica as ideias, o pensamento convergente direciona para uma solução. De acordo com Pauling (apud Brown 2009, p.63) "para ter uma boa ideia, você antes precisa ter muitas ideias". Brown (2009, p.64) considera que "o processo do design thinker se parece com uma transição rítmica entre as fases divergente e convergente, com cada iteração subsequente menos ampla e mais detalhada que as anteriores".

No prefácio de seu livro, Lockwood introduz sua teoria explicando que:

design thinking é essencialmente um processo inovad or centrado no ser humano que enfatiza a observação, colaboração, aprendizado rápido, visualização de ideias, rápida prototipagem de conceitos, e análise de concorrentes, que por fim influência a inovação e a estratégia de negócios. (LOCKWOOD, 2009, p.11)

Na concepção mais simples, Martin (2009, p.62) diz que "design thinking significa pensar como um designer faria". Ainda segundo o Martin (2009, p.58), "design não é sobre fazer coisas bonitas, mas também fazer com que as coisas funcionem lindamente".

acreditamos que o design thinking para negócios se divide em três componentes essências: (1) entendimento profundo e holístico sobre o usuário; (2) visualização de novas possibilidades, prototipagens e refinamentos; e (3) a criação de um novo sistema ativo para trazer ideias nascentes para uma real e rentável operação. (Martin, 2009, p.87)

Para Lockwood (2009, p.63) design thinking "envolve a habilidade de rapidamente visualizar problemas e conceitos, o desenvolvimento de cenários baseado em pessoas, e estratégias de design baseadas nos métodos de pesquisa do designer." A partir disso o autor define cinco aspectos-chave do design thinking:

1. Profundo entendimento do consumidor através de pesquisa de campo. É nesta etapa em que o designer gera os insights, por meio das habilidades de observação, empatia, etnografia, etc.

2. Colaboração com o usuário na formação de grupos multidisciplinares para que trabalhem de forma interdisciplinar.

3. Aceleração do aprendizado por meio da visualização, experimentação e criação de protótipos rápidos. 
4. Habilidade do design thinker em gerar visualização de conceitos.

5. Integrar a análise de negócio durante o processo e não no final.

Apesar da visão do mundo, Martin (2009, p.158) diz que os "design thinkers procuram equilibrar validade com confiabilidade". Para o autor, eles possuem três ferramentas-chave: observação, imaginação e configuração. Observadores têm a habilidade de ver coisas que os outros não veem, isso "requer ver e escutar cuidadosamente de maneira sensível ao assunto, como um etnógrafo faria" (MARTIN, 2009, p.160). Por último, configuração é "traduzir a ideia em um sistema de atividade que irá produzir resultados desejáveis. Brown (2009, p.47) adiciona mais uma ferramenta, e talvez uma das mais importantes, que segundo o autor é "tentativa de ver o mundo através dos olhos dos outros, de compreender o mundo por meio das experiências alheias e de sentir o mundo por suas emoções."

Brown (2009, p.38) enfatiza que o verdadeiro desafio dos design thinkers é "ajudar as pessoas a articular as necessidades latentes que podem nem saber que têm". $O$ autor ainda ressalta que "a próxima geração de designers deverá começar a analisar todos os problemas como um problema de design", ou seja, as novas gerações deverão estar cada vez mais antenadas aos problemas da humanidade para que busquem soluções inovadoras visando o bem-estar sociedade.

\title{
2.3 Design social e design de serviços: a importância da criatividade colaborativa
}

Para a Design21 Social Design Network, rede de design social filiada a Unesco, design social é "o design para o bem maior".

\begin{abstract}
A rede acredita que a verdadeira beleza do design reside no seu potencial para melhorar a vida. Esse potencial primeiro se manifesta como uma série de decisões que resultam em uma série de consequências. A prática do design social considera que estas decisões em maior escala, entendendo que cada passo do processo de design é uma escolha que se perpetua em nossas comunidades, em nosso mundo e em nossas vidas. Essas escolhas são o resultado de ideias informadas, maior consciência, largas conversas e, a mais importante, o desejo de fazer o bem. Design Social é o design para o bem de todos. (DESIGN21, 2012)
\end{abstract}

Segundo Langenbach (2008), o design de serviços surge pela necessidade de trazer uma visão mais humana aos serviços. De acordo com o autor, isso faz com que as novas tecnologias sejam utilizadas pela sociedade, voltadas para uma melhoria na qualidade de vida, sendo, então, projetadas e organizadas de forma a melhorar as relações sociais.

O termo inovação social para Manzini (2008, p.61), "refere-se no modo como indivíduos ou comunidades agem para resolver seus problemas ou criar novas oportunidades". Para o autor, tais inovações são guiadas mais por mudanças de comportamentos do que por mudanças tecnológicas ou de mercado, geralmente emergindo através de processos organizacionais "de baixo para cima", em vez daqueles "de cima para baixo".

A ideia do design de serviços é utilizar parte da metodologia do design de produtos e da comunicação visual para, a partir da sua visão multidimensional, projetar serviços que tenham no seu foco o homem e sua relação social, mas uma relação que amplie o sentido Eu-Tu, valorizando não só o serviço, mas o desejo da troca, não só a relação usuário-serviço, mas também quem está por traz do serviço, valorizando a relação entre os indivíduos - seja quem executa o serviço, seja de quem usufrui dele. (LANGENBACH, 2008, pg. 33)

Para Manzini (2008), existem duas modalidades de atuação no design: (i) projetar para comunidades criativas (designing for), que significa o desenvolvimento de produtos e serviços que possam "intervir em seus contextos para torná-los mais favoráveis, desenvolvendo soluções a fim de aumentar sua acessibilidade, eficácia e consequentemente, sua replicabilidade"; e (ii) projetar 
nas comunidades criativas (designing in), que significa a participação do designer unido aos "outros atores envolvidos na construção de empreendimentos sociais difusos e no co-design de organizações colaborativas". (MANZINI, 2008)

Concluindo o conceito, Langenbach (2008) diz que "co-design significa a participação conjunta no processo de projetar; é o modo participativo de se fazer design, no qual a atividade não é exclusiva do especialista: o designer". O resultado de qualquer projeto seja ele um produto ou serviço tem que servir a sociedade que o utiliza.

Pode-se dizer, enfim, que as comunidades criativas aplicam sua criatividade para quebrar modelos dominantes de pensar e fazer. (MANZINI, 2008, p.65)

\subsection{Inovação para a saúde: a busca pelo bem-estar por meio do design thinking}

Algumas instituições já reconheceram os méritos do papel estratégico que o design proporciona e estão investindo em consultorias terceirizadas, ou até mesmo montando equipes internas de design a fim de melhorar seus serviços através da inovação. Como o caso da prestadora de serviços na área da saúde, Kaiser Permanente citada por Brown (2008), a qual "decidiu melhorar a qualidade geral da experiência dos cuidados médicos do ponto de vista tanto dos pacientes quanto dos profissionais da área médica." A equipe da IDEO sugeriu que "ao invés de contratar um grande número de designers internos, o pessoal aprendesse os princípios do design thinking e os aplicasse" (BROWN, 2008, p.161). Um dos desafios dessa nova equipe foi reformular as trocas de turno do pessoal da enfermagem. Esse trabalho foi primordial para identificar os problemas que normalmente ocorriam nesta etapa, a qual era sistemática em demasia e diferia de um hospital ao outro, fazendo com que as informações fossem mal transmitidas. "O conhecimento de interesse dos pacientes muitas vezes era perdido. (...) A equipe descobriu que muitos pacientes percebiam que a troca de turnos criava um buraco negro no tratamento" (BROWN, 2008, p.162). Tendo conhecimento destes fatos, a equipe, formada não por designers profissionais, mas pelo próprio pessoal da Kaiser, conduziu um autêntico processo design, através de brainstorming, prototipagem, gravação de vídeos, interpretação de anotações rabiscadas em Post-its etc.

O resultado foi uma mudança de abordagem, com enfermeiros trocando informações na frente do paciente, e não na estação de enfermagem (...) e o mais importante: os pacientes passaram a participar do processo e tinham a chance de acrescentar detalhes sobre seu interesse. A Kaiser mensurou o impacto dessa mudança e percebeu que o tempo médio entre a entrada e um enfermeiro no turno e sua primeira interação com um paciente foi reduzido em mais da metade. (BROWN, 2008, p.162)

A partir daí que os enfermeiros, especialistas em desenvolvimento e tecnólogos envolvidos decidiram criar a Kaiser Permanente Innovation Consultancy, uma consultoria em inovação que idealiza o "hospital do futuro" incorporando inovação e design thinking por toda a organização. Os designers da IDEO também tiveram participação importante na criação do Centro para Inovação (CFI) da organização sem fins lucrativos líder mundial em assistência médica, pesquisa e educação, a Mayo Clinic.

Em 2002, em consultoria com IDEO, os médicos Nicholas LaRusso e o colega Dr. Michael Brennan abriram um laboratório ambulatorial skunkwork chamado SPARC, onde os médicos e designers podiam testar hipóteses sobre as formas em que provedores e pacientes interagiam. Eles lidaram com uma série de desafios: recrutando médicos ocupados para um novo e não testado tipo de pesquisa, atravessando a diferença cultural entre médicos e designers, fazendo experiências com pacientes reais e, ganhando apoio institucional para seu esforço incomum. (YALE SCHOOL OF MANAGEMENT, 2012) 
Seu estúdio de design e pesquisa "não só observa pacientes, entrevista famílias e conduz pesquisas de consumidor tradicionais, como também visualiza, modela, faz protótipos e testa possíveis soluções na prestação de cuidados em saúde, criando inovações." (MAYO CLINIC, 2012)

Dentro de seis anos, o pequeno laboratório de pesquisa se transformou em um grande Centro de Inovação para toda a organização. O CFI é hoje um "instituto de pesquisa dedicado que estuda o processo de prestação de cuidados de saúde, desde o primeiro telefonema, à visita à clínica, ao diagnóstico e tratamento do problema, ao acompanhamento e cuidados preventivos." (YALE SCHOOL OF MANAGEMENT, 2012)

Um exemplo do trabalho do CFI foi o projeto Jack and Jill Rooms, feito junto à Divisão Geral de Medicina Interna e ao Departamento de Instalações. Trata-se de uma readequação de uma sala de consulta, a qual foi separada em dois ambientes como mostra a Figura 1 abaixo. De um lado, uma sala de conversação equipada com somente um instrumento médico: um aparelho medição de pressão. Do outro lado, separado apenas por uma porta, há a sala de exame com os instrumentos necessários para uma análise clínica.

Os médicos gostam de ter um lugar pra conversar com os pacientes, onde possam ver o monitor e incluir os membros da família. Eles descobriram também que ter uma sala de exames sem sofá e mesa permitiu que a cama e as ferramentas fossem reorganizadas, tornando o exame físico mais fácil para eles. (MAYO CLINIC, 2012)

Figura 1 - Jack and Jill Rooms - sala de conversação e de exames
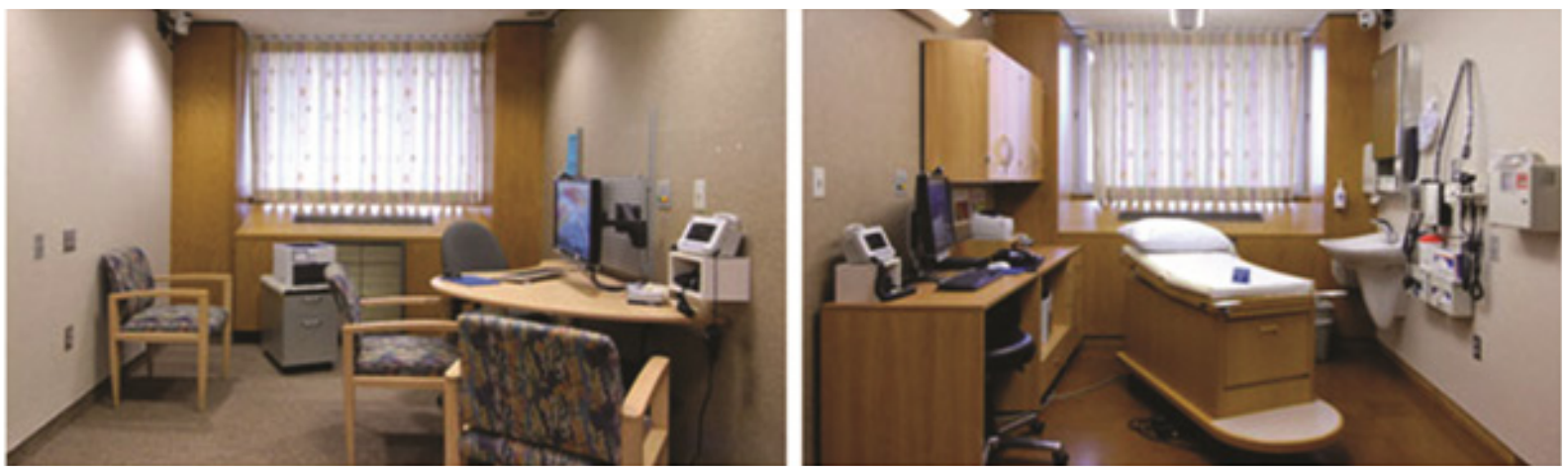

Fonte: MAYO CLINIC (2012)

Isso foi determinante para transformar este num ambiente confortável para os pacientes, onde se sintam menos intimidados pelos instrumentos médicos e menos constrangidos na sala exames. A sala de conversação serve para criar um ambiente colaborativo onde médico e paciente dialogam antes e depois do exame.

Quando se trata de prevenção, a abordagem do design thinking pode ajudar muito as pessoas a diagnosticarem uma doença antes mesmo de consultar um médico. Durante suas pesquisas sobre câncer de mama, a designer norte-americana Corrine Ellsworth Beaumont descobriu que haviam muitas informações confusas e contraditórias nos materiais de comunicação sobre o assunto, principalmente nas informações sobre nódulos malignos que podem surgir nos seios pois metade dos pacientes não sabiam como sentir um nódulo.

Além disso, ficou constatado que existem muitos tabus que podem tornar as campanhas públicas dificultosas.

Primeiro, o seio é geralmente associado a sexo, e a exibição de imagens de seios pode ser um problema. Segundo, câncer é geralmente associado com a morte, tornando-se um tema que para muitos é difícil de discutir, fazendo com que muitas pessoas o evitem completamente. (Worldwide Breast Cancer, 2012) 
A partir daí que surgiu o desafio de design para Beaumont: fazer uma apresentação atrativa, completa, fácil de compartilhar e que trouxesse informação clara o suficiente para aqueles tinham medo ou vergonha, ou para os que estivessem desinteressados ou sobrecarregados sobre o assunto.

Figura 2 - Comparação entre o método de ilustração tradicional e a metáfora visual
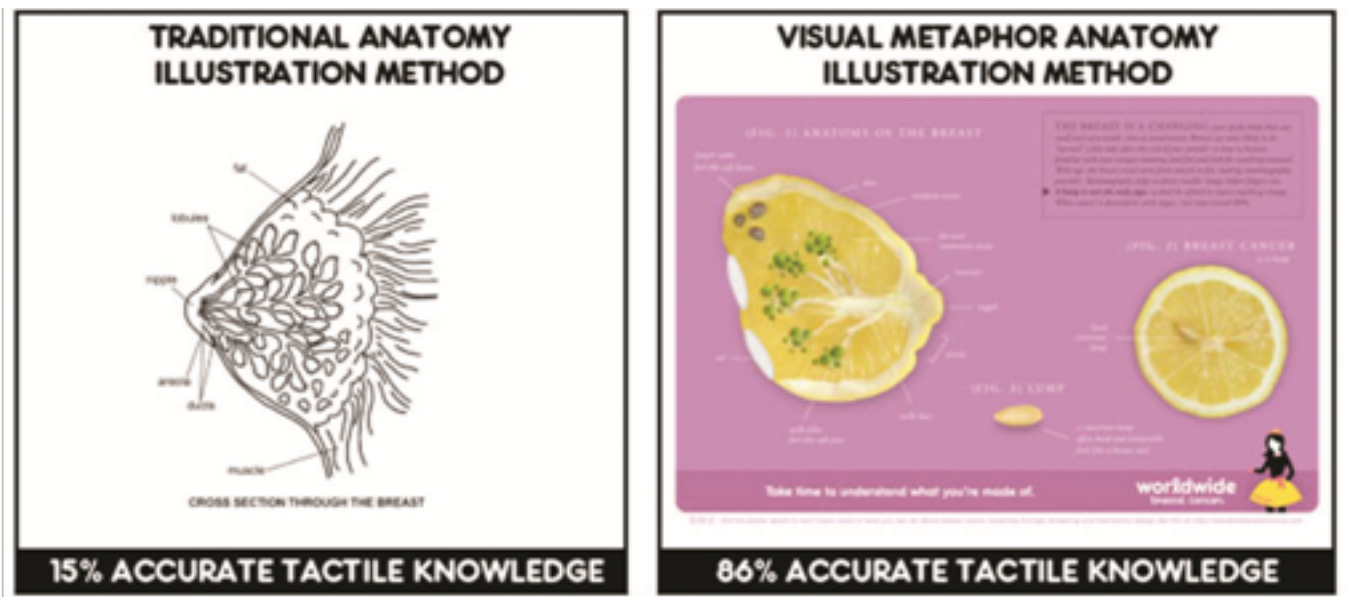

Fonte: WORLDWIDE BREAST CANCER (2012)

Figura 3 - Pôster ilustrativo da campanha Worldwide Breast Cancer

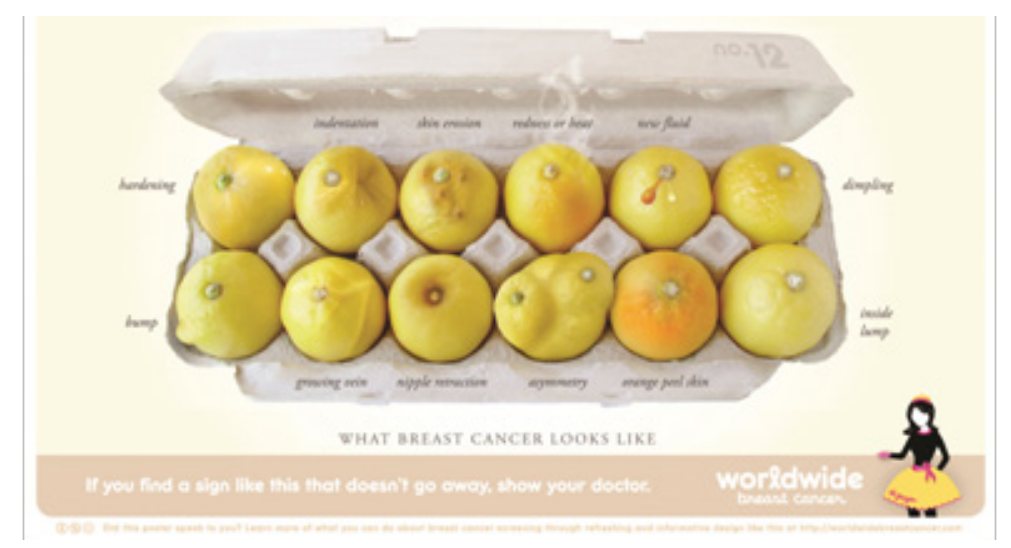

Fonte: WORLDWIDE BREAST CANCER (2012)

A proposta da campanha Worldwide Breast Cancer foi remover a conotação sexual e de morte da mensagem sobre câncer de mama utilizando uma metáfora de um limão para representar o seio. "Mais do que apenas uma fruta simpática, limões tem a forma semelhante à de um seio por fora e se assemelha à anatomia de um seio por dentro" (WORLDWIDE BREAST CANCER, 2012). No primeiro pôster (Figura 3), uma imagem de vários limões com diferentes deformidades representa diferentes tipos de anormalidades que simbolizam diferentes sintomas de câncer de mama. Já no segundo pôster (Figura 2), um limão cortado ao meio representando a anatomia de um seio, em que a semente se assemelha a um nódulo.

\section{METODOLOGIA}

O presente artigo se define pela pesquisa qualitativa, de natureza exploratória e caráter 
descritivo. Optou-se pela pesquisa qualitativa pois ela possibilita uma melhor compreensão do universo da população em questão, permitindo um entendimento mais humano perante os fenômenos e mudanças em um processo social. Pesquisa qualitativa é basicamente aquela que busca entender um fenômeno específico em profundidade. Ao invés de estatísticas, regras e outras generalizações, a qualitativa trabalha com descrições, comparações e interpretações. A pesquisa qualitativa é mais participativa e, portanto, menos controlável. Os participantes da pesquisa podem direcionar o rumo da pesquisa em suas interações com o pesquisador.

Segundo Lakatos e Marconi (1999), os estudos de natureza exploratória são

investigações de pesquisa empírica cujo objetivo é a formulação de questões ou de um problema, com tripla finalidade: desenvolver hipóteses, aumentar a familiaridade do pesquisador com um ambiente, fato ou fenômeno, para a realização de uma pesquisa futura mais precisa ou modificar e clarificar conceitos. (LAKATOS E MARCONI, 1999, p. 87)

Em função disso, este trabalho pretende buscar novos conhecimentos, assim como proporcionar novas perspectivas a respeito do tema, que até então, era pouco conhecido.

De acordo com Gil (1991), as pesquisas descritivas possuem como objetivo a descrição das características de uma população, fenômeno ou de uma experiência. Neste caso, pretende-se investigar as experiências vivenciadas por crianças diagnosticadas com câncer.

Quanto ao delineamento de pesquisa e seus procedimentos de coleta de dados, foi utilizado o método de pesquisa de campo. Foram realizadas entrevistas na forma de roteiro aberto semiestruturado, com pessoas previamente selecionadas, por meio de uma sequência de perguntas tendo como objetivo obter um levantamento qualitativo dos problemas bio-psico-sociais enfrentados por pacientes e família durante o tratamento de câncer infantil. Acredita-se que este tipo de entrevista permite um melhor compartilhamento de experiências se conduzida de forma participativa, na qual o pesquisador deixe claras as intenções positivas de seu trabalho, afim de que o público entrevistado sinta-se mais à vontade em colaborar com a pesquisa.

Porém, foi constatado que somente a pesquisa de campo não seria suficiente para obter conhecimentos necessários perante o problema, o que podia limitar uma análise mais profunda e, consequentemente, restringir uma possível proposição de diretrizes. Para isso, decidiu-se adotar também o método de pesquisa etnográfica.

A etnografia é para Hammersley e Atkinson (1994) a "forma mais básica de investigação social e que trabalha com uma ampla gama de fontes de informações." Além de ser um método qualitativo extremamente valioso, é também uma das principais ferramentas do design thinking, pois possibilita a visão empática.

Não é um simples método de coleta de dados, mas um método que procura entender como a cultura ou sub-cultura, ao mesmo tempo construída e formulada pelo comportamento humano e suas experiências, pode explicar padrões de comportamento. (IKEDA; PEREIRA; GIL, 2006, p.5)

\section{RESULTADOS}

\subsection{Entrevistas}

Para o presente artigo foram realizadas duas entrevistas por meio de uma sequência de perguntas norteadas pelos assuntos indicados no quadro a seguir:

Quadro 1 - Assuntos que nortearam as entrevistas 
Contribuições de Design Thinking à humanização do tratamento de câncer infantil

\begin{tabular}{|c|c|c|c|}
\hline $\begin{array}{l}\text { UNIDADES } \\
\text { DE ANÁLISE }\end{array}$ & $\begin{array}{l}\text { VARIÁVEIS DA } \\
\text { UNIDADE DE ANÁLISE }\end{array}$ & ORIGEM & $\begin{array}{l}\text { NORTE PARA ROTEIRO } \\
\text { DE ENTREVISTAS }\end{array}$ \\
\hline $\begin{array}{l}\text { Gestão do } \\
\text { Conhecimento }\end{array}$ & $\begin{array}{l}\text { - dados, informação e conhecimento } \\
\text { - conhecimentos tácito, explícito, } \\
\text { cultural, subjetivo e objetivo } \\
\text { - conversão do conhecimento }\end{array}$ & $\begin{array}{l}\text { - Nonaka e Takeuchi } \\
\text { (1997); } \\
\text { - Choo (2003); } \\
\text { - Popper (1975); } \\
\text { - Firestone e McElroy } \\
\text { (2003) }\end{array}$ & $\begin{array}{l}\text { - qual era o nível de informação dos pais sobre } \\
\text { o câncer; } \\
\text { - de que forma médicos explicitaram seus } \\
\text { conhecimentos; } \\
\text { - influência do conhecimento cultural para a } \\
\text { experiência; } \\
\text { - até que ponto o conhecimento subjetivo } \\
\text { limitado da criança interfere no tratamento. }\end{array}$ \\
\hline Design Thinking & $\begin{array}{l}\text { - entendimento sobre o usuário } \\
\text { - visualização de novas possibilidades } \\
\text { - colaboração com o usuário na } \\
\text { formação de grupos multidisciplinares } \\
\text { - ajuda na articulação de necessidades } \\
\text { latentes }\end{array}$ & $\begin{array}{l}\text { - Brown (2009); } \\
\text { - Lockwood (2009); } \\
\text { - Martin (2009) }\end{array}$ & $\begin{array}{l}\text { - quais as expectativas, anseios e dúvidas dos } \\
\text { pais; } \\
\text { - quais as necessidades do paciente; } \\
\text { - como é a expêriencia de tratamento de } \\
\text { câncer; } \\
\text { - o que pode ser melhorado, mantido ou } \\
\text { descartado. }\end{array}$ \\
\hline $\begin{array}{l}\text { Design Social } \\
\text { e Design de } \\
\text { Serviços }\end{array}$ & $\begin{array}{l}\text { - visão mais humana aos serviços } \\
\text { - inovação social } \\
\text { - processos organizacionais "de baixo } \\
\text { para cima" } \\
\text { - comunidades criativas (co-design) }\end{array}$ & $\begin{array}{l}\text { - Langenbach (2008); } \\
\text { - Manzini (2008); } \\
\text { - Détienne (2004) }\end{array}$ & $\begin{array}{l}\text { - conduta dos profissionais de saúde; } \\
\text { - preocupação dos profissionais com o bem- } \\
\text { estar do paciente; } \\
\text { - colaboração entre profissionais de diferentes } \\
\text { especialidades; } \\
\text { - jornada do paciente. }\end{array}$ \\
\hline
\end{tabular}

A seleção do público foi feita sobre o critério de que as pessoas entrevistadas teriam que ser responsáveis pelos cuidados de crianças tratadas de câncer que obtiveram cura. Esses têm maiores condições de oferecer relatos consistentes de todas as etapas do processo tais como prevenção, diagnóstico, tratamento, recuperação, acompanhamento e reinserção na sociedade. As entrevistas foram realizadas nas residências dos entrevistados, pois se acredita que este seja um ambiente favorável para uma conversa mais aberta. As conversas foram registradas por meio de gravação em áudio e optou-se por descrever as entrevistas na íntegra porque se acredita que dessa forma é possível obter uma análise humanizada perante a situação.

\subsection{Entrevista A}

Miguel: Gostaria de saber com qual tipo de câncer seu filho foi diagnosticado. Quais eram as chances de cura? Como está sendo a recuperação?

Entrevistada A: Ele teve leucemia linfóide de alto risco. Por isso ele passou por um período de tratamento mais longo, recebendo uma quantidade de droga maior. No caso, o período de tratamento foi de três anos e dois meses. Como não houve nenhuma recaída, não foi preciso o transplante de medula. O primeiro ano de acompanhamento é o mais delicado, pois se houver qualquer recaída a solução será o transplante de medula. Porém, se isso ocorrer, temos o conforto de saber que temos um doador dentro de casa, já que o irmão é $100 \%$ compatível.

Miguel: Antes do diagnóstico, os pais já sabiam dos sintomas que caracterizam o câncer infantil?

Entrevistada A: Na realidade eu não tinha. O diagnóstico foi muito tardio. Quando o meu filho fica doente ele não tem muitos sintomas. $O$ que eu percebi nele foram algumas manchas vermelhas espalhadas pelo corpo. Isso ocorreu numa sexta-feira, nisso imediatamente para o pediatra e marquei uma consulta para a segunda-feira. Após a consulta eu o levei para fazer todos os exames que constaram que seu quadro era realmente grave. Isso com que ele fosse internado naquela noite.

Por mais que eu seja uma mãe que peca pelo excesso de zelo, passar por essa situação é a ultima coisa que passa pela nossa cabeça.

Miguel: Você acha que deveria existir uma forma de comunicação mais abrangente de forma que esse assunto fosse mais bem esclarecido? Concorda que, se tivessem recebido informações com antecedência, poderia ter diagnosticado a doença mais cedo?

Entrevistada A: Acho que sim. A gente que tem acesso à informação é diferente de quem não tem. Quem tem mais problema com isso são as pessoas menos privilegiadas, principalmente quem depende do sistema público de saúde. Para essas pessoas acho que devia sim existir uma forma melhor 
de comunicação sobre a doença. Essas pessoas menos favorecidas não têm o mesmo acesso que temos, e acabam procurando atendimento de posto de saúde em que tudo é virose. Enfim, a conscientização tem que ser mais voltada para sintomas mesmo.

Miguel: Qual era a perspectiva da criança perante o diagnóstico? Ela sabia da gravidade da doença? Essa informação foi omitida?

Entrevistada A: Não tivemos nenhum problema com isso. Ele sabe, nunca o foi negado. Porém a expectativa era como contar para o irmão, pois por ele ser mais velho, ele sabia o que era câncer.

Miguel: Como foi o discurso do médico? Qual o tom de suas palavras?

Entrevistada A: A médica é sensacional! Sempre teve um discurso de esperança, com palavras positivas. Outra coisa muito importante que ela faz é esclarecer e mostrar tudo para as mães. Isso tranquiliza ao mesmo tempo em que pode causar ansiedade em alguns. Porém, quando você vai conhecendo um pouco de tudo geralmente você fica mais tranquilo.

Miguel: Você acha que essa conduta é específica dela?

Entrevistada A: Acho que é específica dela e acho que todos os médicos deviam fazer isso. Eu já ouvi de outras pessoas tratadas por outros médicos que nem todos têm essa preocupação. Ela marcava as consultas de todas as crianças no mesmo dia. A troca de informação, a troca de experiências e a liberdade de você poder falar o que quiser é muito importante e só acontece naquele contexto.

Miguel: Como foi o tratamento no hospital?

Entrevistada A: Começou muito tenso. A princípio o meu filho ficou internado por 10 dias no $\mathrm{HE}$. Depois disso tivemos que ser transferidos para o HCL. Isso foi um desespero porque o HCL pra mim era um mito gigante. Eu morria de medo daquele lugar. Porém, essa transição foi demais! Fui muito bem acolhida. Acho que precisaria desmistificar aquele lugar. As pessoas deveriam receber mais informações do trabalho e de como as coisas realmente funcionam lá dentro. Eu briguei muito lá dentro para que mudassem algumas coisas. Principalmente por causa do corporativismo interno. Tudo o que pude fazer pra melhorar o atendimento eu fiz, não só em prol de meu filho, mas de todos ali dentro. Mas eu sinto que eles querem mudar isso. Temos que levar o hospital pra dentro das casas das pessoas.

Miguel: Ele sentia falta da escola e dos amigos nesse tempo?

Entrevistada A: Sim, e isso foi um grande problema. Tinha períodos que não ele podia sair de casa. O contato com os amiguinhos era somente através de uma janela.

Miguel: Qual foi a reação de colegas, professores e amigos? Ele sofreu preconceito?

Entrevistada A: A reação foi de pânico por parte de alguns. Com as crianças pequenas não aconteceu porque não sabiam muito do que se tratava. Mas ele tem alguns primos mais velhos e com eles foi preciso mais cuidado na comunicação sobre essa situação. Acho que, por ele ser mais novinho, ele sofreu menos preconceito do que sofreria se tivesse a idade do irmão. Talvez se o hospital chegasse à casa das pessoas, essas crianças que tem preconceito iriam enxergar o problema de outra forma.

Miguel: Como era a relação com os profissionais de saúde no hospital? Eram abertos a sugestões e críticas?

Entrevistada A: Os profissionais de saúde lá dentro são excelentes. Eram muito abertos nesse sentido. Alguns se tornaram amigos nossos. Eu só tive problemas mesmo com a parte administrativa. Acho que a hierarquia e alguns impasses prejudicam os procedimentos.

Miguel: Os horários para visita eram limitados?

Entrevistada A: Era extremamente limitado. É muito duro ficar sozinho nessa hora. Por mais que você se esforce, é difícil tornar aquilo lúdico. Acho que, se realmente é importante para a recuperação dos pacientes, temos que respeitar. Agora, pensando no bem-estar, eu acho pouco. Creio que deveria ser mais humanizado essa história. Por que não fazer do hospital uma extensão da casa? Em minha opinião o hospital deveria melhorar também a acomodação do acompanhante, principalmente no quesito mobiliário que é geralmente muito desconfortável.

Miguel: O que você gostaria de mudar em relação ao comportamento dos profissionais?

Entrevistada A: O profissional da saúde, principalmente no $\mathrm{HCL}$, vai ficando muito duro com o tempo. Ele acaba esfriando, se endurecendo por causa daquele ambiente. Acho que precisa humanizar um pouco mais esse profissional, não deixando chegar nesse ponto. Capacitados eles são, só precisam estar mais motivados. 


\subsection{Entrevista B}

Miguel: Você sabia dos sintomas que caracterizam o câncer? Concorda que, se tivesse recebido informações com antecedência, poderiam ter diagnosticado a doença mais cedo?

Entrevistada B: Não sabia. Descobri que meu filho tinha meduloblastoma quando ele tinha sete anos. Concordo sim, porque quando eu o levei ao posto de saúde, o pediatra disse que o menino estava com enxaqueca, não fez nenhum exame e recomendou que ele voltasse pra casa e que tomasse somente um remédio para dor. A partir daí o quadro foi piorando. Ele começou a ter dor de cabeça seguida de vômito e perda de equilíbrio. Ele começou a cair muito. Ele andava na rua normalmente e de repente caia. Nesse período, ele tinha um acompanhamento na escola onde algumas pediatras consultavam as crianças. Eu falei pra médica sobre os sintomas que ele estava tendo. Ela fez um exame simples e solicitou que o levássemos a um hospital para fazer uma tomografia. No dia seguinte eu o levei ao HISF para fazer esse exame e, já na parte da tarde, saiu o resultado que ele tinha um tumor na cabeça do tamanho de uma laranja. $\mathrm{O}$ câncer estava bem avançado.

Miguel: A criança sabia da gravidade da doença?

Entrevistada B: Ele sabia, mas não tinha noção da gravidade.

Miguel: Os médicos se dispuseram a esclarecer as dúvidas sobre o assunto? De que forma foi trabalhada a informação?

Entrevistada B: Eles me esclareceram tudo, mas não davam expectativa de vida devido ao quadro muito grave. Mostraram-me todos os exames indicando em lugar do corpo o tumor se encontrava, qual seu tamanho, qual a gravidade, os riscos que meu filho corria etc. Eles foram bem realistas e diretos dizendo que o que ele tinha era grave e poderia morrer na cama, na mesa de operação, em qualquer momento.

Miguel: A criança reagiu bem ao tratamento? Ela apresentou alguma resistência?

Entrevistada B; Ele não podia levantar da cama. Tinha que se manter deitado o tempo todo. Ele chegou a ter um pouco de depressão. Fora isso, ele reagiu muito bem, foi muito calmo. Ele só não gostava muito de fazer fisioterapia.

Miguel: Qual foi a reação dos colegas, professores, amigos?

Entrevistada B: Ele ficou um ano afastado da escola. Durante esse período os colegas de classe e professores enviaram cartinhas prestando apoio.

Miguel: Na volta para escola, ele sofreu algum tipo de preconceito por estar careca?

Entrevistada B: Sim, ele sofreu muito com isso quando voltou para a escola. No começo foi difícil, ele chorava muito e não queria voltar pra escola. Mas depois ele foi superando.

Miguel: Como foi a relação com os profissionais de saúde? Prestaram o apoio necessário? Acha que foi bom o suficiente ou poderia ser melhor?

Entrevistada B: $\mathrm{O}$ atendimento foi muito bom, eles foram bem prestativos. Elas foram ótimas profissionais. Tinham umas até que eram evangélicas e ofereciam ajuda espiritual, traziam palavras de esperança. Eu só tive problema mesmo com uma enfermeira do HISF que cometeu um descuido na hora de higienizar o cateter instalado na cabeça do menino.

Miguel: Os profissionais eram abertos a sugestões e críticas?

Entrevistada B: Sim. Às vezes uma enfermeira tinha dificuldade de achar a veia. Isso judiava e furava muito a criança. Quando isso acontecia, eu pedia para que outra enfermeira fizesse o procedimento. Mas isso não afetava a relação com elas.

Miguel: Qual restrição você gostaria de mudar?

Entrevistada B: O horário de troca de acompanhante. Era difícil porque era muito tarde, eu tinha que trocar às nove horas da noite. Eu precisava vir embora de ônibus e a pessoa que trocava comigo também tinha que ir de ônibus, e esse horário tardio dificultava.

\subsection{Etnografia}

Para enriquecer a pesquisa, foi realizado um estudo etnográfico no setor de oncopediatria de um hospital situado na cidade de Londrina-PR, buscando identificar a percepção dos pacientes e acompanhantes sobre a convivência naquele universo. Constatou-se que o que foi observado na etnografia foi suficiente para complementar os dados obtidos por meio de entrevistas, o que possibilitou 
a identificação de oportunidades de intervenção.

As observações se dividiram em duas fases. A primeira, ocorrida nas primeiras duas horas, quando o pesquisador foi apresentado aos pacientes e profissionais do setor. Esse período de observação não participativa foi reservado para o registro de imagens das acomodações. A fase seguinte foi constituída pela observação participativa em que se iniciaram as conversas informais, tendo como objetivo criar um ambiente amistoso e contextualizar o cenário cultural em estudo.

Grande parte do que foi observado vai ao encontro com os relatos registrados nas entrevistas, especialmente no que se refere ao comportamento acolhedor dos profissionais. Notou-se que a relação entre médicos, enfermeiras, assistentes sociais, pacientes e acompanhantes é muito amistosa, assemelhando-se muito a um ambiente familiar. Além disso, existem instituições de apoio instaladas em torno do hospital que oferecem suporte para as famílias mais necessitadas. Muitos acompanhantes recorrem a uma ONG que oferece refeições e fornece alimentos e produtos de higiene pessoal.

Em nível de estrutura física, foram analisados aspectos como acomodações dos quartos, sala de espera, equipamentos de auxílio para deslocamento, brinquedos, entre outros. De acordo com alguns colaboradores, no passado a sala de espera era única, onde pacientes adultos e crianças se misturavam. Além disso, as crianças beneficiadas por convênio médico eram separadas das demais. Hoje isso mudou, todas as crianças são tratadas no mesmo setor e o quarto dos pacientes do SUS tem praticamente a mesma estrutura dos pacientes conveniados. Todos os quartos são equipados com televisão de plasma e decorados com papéis de parede ilustrados. A sala de espera e convivência conta com diversos brinquedos, televisão, vídeo game, instrumentos musicais, banheiros e um espaço reservado para refeições. Acredita-se que pacientes e acompanhantes passam boa parte do tempo nesta sala devido à necessidade de socialização e entretenimento. Enquanto as mães conversam, as crianças ou assistem televisão ou passam o tempo no computador, já que algumas possuem seus próprios laptops. Notou-se também que elas ficam incomodadas ao se locomover carregando o suporte para soro. Uma mãe chegou a apelidar o equipamento de "pitbull".

Por meio das conversas com as crianças, constatou-se que, assim como os depoimentos das entrevistas, elas sentem muita falta da escola e dos amigos. Outro aspecto em comum foi o questionamento referente aos horários de espera e troca. De acordo com uma médica, as crianças pequenas lidam melhor com a doença do que os adolescentes pelo fato de que, por serem mais velhos, possuem um conhecimento maior a respeito da doença e suas consequências, podendo causar ansiedade e perda de auto-estima.

\subsection{Análise de Resultados}

Os resultados obtidos por meio das duas entrevistas foram sintetizados no Quadro 2.

Quadro 2 - Resultados obtidos por meio de entrevistas

\begin{tabular}{|c|c|c|c|}
\hline $\begin{array}{l}\text { UNIDADES } \\
\text { DE ANÁLISE }\end{array}$ & $\begin{array}{l}\text { VARIÁVEIS DA } \\
\text { UNIDADE DE ANÁLISE }\end{array}$ & $\begin{array}{l}\text { NORTE PARA ROTEIRO } \\
\text { DE ENTREVISTAS }\end{array}$ & RESULTADOS \\
\hline $\begin{array}{l}\text { Gestão do } \\
\text { Conhecimento }\end{array}$ & $\begin{array}{l}\text { - dados, informação e conhecimento } \\
\text { - conhecimentos tácito, explícito, } \\
\text { cultural, subjetivo e objetivo } \\
\text { - conversão do conhecimento }\end{array}$ & $\begin{array}{l}\text { - qual era o nível de informação dos pais } \\
\text { sobre o câncer; } \\
\text { - de que forma médicos explicitaram seus } \\
\text { conhecimentos; } \\
\text { - influência do conhecimento cultural para a } \\
\text { experiência; } \\
\text { - até que ponto o conhecimento subjetivo } \\
\text { limitado da criança interfere no tratamento. }\end{array}$ & $\begin{array}{l}\text { - baixo nível de } \\
\text { informação; } \\
\text { - externalização e } \\
\text { combinação; } \\
\text { - conhecimento cultural } \\
\text { deve se tornar explicito; } \\
\text { - crianças mais novas tem } \\
\text { menos ansiedade. }\end{array}$ \\
\hline
\end{tabular}


Contribuições de Design Thinking à humanização do tratamento de câncer infantil

\begin{tabular}{|c|c|c|c|}
\hline $\begin{array}{l}\text { UNIDADES } \\
\text { DE ANÁLISE }\end{array}$ & $\begin{array}{l}\text { VARIÁVEIS DA } \\
\text { UNIDADE DE ANÁLISE }\end{array}$ & $\begin{array}{l}\text { NORTE PARA ROTEIRO } \\
\text { DE ENTREVISTAS }\end{array}$ & RESULTADOS \\
\hline $\begin{array}{l}\text { Gestão do } \\
\text { Conhecimento }\end{array}$ & $\begin{array}{l}\text { - dados, informação e conhecimento } \\
\text { - conhecimentos tácito, explícito, } \\
\text { cultural, subjetivo e objetivo } \\
\text { - conversão do conhecimento }\end{array}$ & $\begin{array}{l}\text { - qual era o nível de informação dos pais } \\
\text { sobre o câncer; } \\
\text { - de que forma médicos explicitaram seus } \\
\text { conhecimentos; } \\
\text { - influência do conhecimento cultural para a } \\
\text { experiência; } \\
\text { - até que ponto o conhecimento subjetivo } \\
\text { limitado da criança interfere no tratamento. }\end{array}$ & $\begin{array}{l}\text { - baixo nível de } \\
\text { informação; } \\
\text { • externalização e } \\
\text { combinação; } \\
\text { - conhecimento cultural } \\
\text { deve se tornar explicito; } \\
\text { - crianças mais novas tem } \\
\text { menos ansiedade. }\end{array}$ \\
\hline Design Thinking & $\begin{array}{l}\text { - entendimento sobre o usuário } \\
\text { - visualização de novas } \\
\text { possibilidades } \\
\text { - colaboração com o usuário } \\
\text { na formação de grupos } \\
\text { multidisciplinares } \\
\text { - ajuda na articulação de } \\
\text { necessidades latentes }\end{array}$ & $\begin{array}{l}\text { - quais as expectativas, anseios e dúvidas dos } \\
\text { pais; } \\
\text { - quais as necessidades do paciente; } \\
\text { - como é a experiência de tratamento de } \\
\text { câncer; } \\
\text { - o que pode ser melhorado, mantido ou } \\
\text { descartado. }\end{array}$ & $\begin{array}{l}\text { - expectativa ruim } \\
\text { transformada em alivio } \\
\text { devido aos bons cuidados; } \\
\text { - exames, terapias, } \\
\text { internaçöes, medicações; } \\
\text { - visitas e troca de } \\
\text { acompanhates }\end{array}$ \\
\hline $\begin{array}{l}\text { Design Social } \\
\text { e Design de } \\
\text { Serviços }\end{array}$ & $\begin{array}{l}\text { - visão mais humana aos serviços } \\
\text { - inovação social } \\
\text { - processos organizacionais "de baixo } \\
\text { para cima" } \\
\text { - comunidades criativas (co-design) }\end{array}$ & $\begin{array}{l}\text { - conduta dos profissionais de saúde; } \\
\text { - preocupação dos profissionais com o bem- } \\
\text { estar do paciente; } \\
\text { - colaboração entre profissionais de } \\
\text { diferentes especialidades; } \\
\text { - jornada do paciente. }\end{array}$ & $\begin{array}{l}\text { - boa conduta } \\
\text { - ambiente familiar } \\
\text { - troca de experiências } \\
\text { - agilidade de processos } \\
\text { burocráticos } \\
\text { - filantropia }\end{array}$ \\
\hline
\end{tabular}

Ficou evidente a semelhança dos pontos de vista levantados nas entrevistas com o que foi observado na pesquisa etnográfica. Quando questionados sobre a perspectiva que as pessoas tinham sobre o $\mathrm{HCL}$, muitos demonstraram que tinham um pouco de preconceito quanto à reputação negativa que o hospital tinha no passado. Hoje, porém, quem passou pela a experiência de tratamento de câncer infantil, reconhece por unanimidade que o atendimento é espetacular e que todos são bem acolhidos. Existe um esforço muito grande por parte da atual direção do hospital em reverter essa imagem negativa. Essa lacuna pode servir como oportunidade para a intervenção pelo design. Tomando como exemplo a frase de uma das mães entrevistadas, "o hospital tem que entrar nas casas das pessoas".

Essa e outras questões levantadas durante as pesquisas podem servir como insights para melhorias por meio do design thinking, assim como a decoração e ambientação dos corredores e salas, a prevenção da doença, o afastamento da escola, os momentos de visita, a produção de materiais educativos que tratem a reinserção da criança na sociedade e por fim, o design dos móveis e equipamentos hospitalares. Tudo pode ser tratado como um problema de design.

A readequação da decoração, do mobiliário e de alguns equipamentos faz toda a diferença para o conforto daqueles que convivem no ambiente hospitalar. O designer pode contribuir projetando móveis e equipamentos adequados às necessidades dos pacientes e acompanhantes. Pode criar suportes para soro mais ergonômicos, com formas que despertam a imaginação das crianças. Ou então reestilizar as cadeiras de rodas, "disfarçando-as" de carros esportivos, carrinhos de bebê, naves espaciais, entre outras formas. Com a tecnologia é possível criar painéis digitais em que as crianças possam interagir de maneira virtual com seus colegas no período de isolamento.

Conforme os resultados apresentados nas entrevistas, é essencial que haja novas formas de comunicação que busquem a prevenção da doença e a reinserção da criança na sociedade. A partir disso, os designers podem criar materiais educativos que, não só conscientize, mas que também estimule pais, professores e médicos no sentido de adotarem medidas preventivas.

No que tange a parte de serviços, há uma necessidade em humanizar os horários de visita. Existem algumas limitações impostas que infelizmente não podem ser mudadas por questão de controle de contaminação. Os pacientes de quimioterapia passam por uma fase de isolamento em que não podem ter contato com outras pessoas. Neste caso, uma equipe de design thinkers pode criar alternativas à visita presencial, desenvolvendo novos sistemas em que paciente e visitante possam interagir virtualmente, ou projetar espaços físicos devidamente isolados para que haja, pelo menos, contato audiovisual. 
Os resultados dessa pesquisa serviram como inspiração para o surgimento de novas ideias. Isso caracteriza a fase divergente do pensamento do designer. Para obter resultados contundentes, é fundamental que tenham pessoas trabalhando na convergência e implementação dessas ideias, ou seja, é preciso formar novos design thinkers.

\section{CONSIDERAÇÕES FINAIS}

Considerando que identificar oportunidades de intervenção por meio do design thinking é muito importante para a humanização do tratamento de câncer pediátrico, foi possível levantar algumas conclusões. Levando-se em conta que este é um assunto relativamente novo e pouco investigado, a pesquisa realizada a respeito desse tema despertou alguns apontamentos relevantes para a continuidade de novos estudos na área.

As pesquisas qualitativas permitiram uma maior aproximação entre o pesquisador e seu objeto de estudo. Antes do início das pesquisas, tinha-se em mente que a ótica do público perante a reputação do hospital ainda era um pouco obscura. Porém, a confiança que as mães depositam nos profissionais e, acima de tudo, o carinho que os mesmos têm pelas crianças superou as expectativas que o pesquisador tinha a respeito da relação.

o que os médicos e enfermeiros tinham com seus pacientes. A partir dessa constatação, concluiu-se que, o atendimento por parte dos profissionais de saúde é muito bem humanizado e que essa condição pode favorecer a intervenção do design thinking por outros caminhos. A observação empática ajuda os pesquisadores a compreender a realidade, as expectativas e anseios através dos olhos dos pacientes. Com isso, verificou-se que o problema da humanização não está na questão do relacionamento entre profissionais e crianças, mas sim em questões estruturais. Baseado nesse argumento, a prática dessa filosofia nas instituições de saúde se torna indispensável. Esse modelo de gestão tem potencial em engajar servidores, médicos, psicólogos, assistentes sociais ou até mesmo pacientes no sentido de formar novas equipes inovadoras, que almejem a humanização de seus tratamentos.

Só é possível identificar as reais necessidades do paciente quando se vivencia a experiência. Isso ocorre por meio de compartilhamento de ideais, troca de opiniões, análise de comportamentos, análise de interações, entre outros. Durante a pesquisa de campo comprovou-se que essa habilidade de articular, produzir, construir e decodificar o conhecimento é própria do design thinker. A busca pelo entendimento do usuário, o compartilhamento de ideias, a identificação de oportunidades, a solução criativa, a experimentação e implementação de novos sistemas fazem parte de sua essência.

Como mencionado na fundamentação teórica, por mais que seja recente e pouca explorada no Brasil, a prática do design thinking vem conquistando espaço em muitas instituições ao redor do mundo, principalmente em países desenvolvidos, onde o design é bem respeitado. Em nosso país o design ainda está em processo de amadurecimento. Se faz necessário sensibilizar empresários e governantes sobre a importância desse modelo de gestão e, principalmente, incentivar novas pesquisas acadêmicas direcionadas ao tema.

O escopo da pesquisa teve que ser demasiadamente reduzido devido ao curto prazo para desenvolvimento de artigo, ao pouco tempo disponível para realização de pesquisa por parte do pesquisador, a escassez de literatura sobre o tema e a dificuldade de se encontrar pessoas que se encaixassem nos critérios de inclusão ou no perfil desejado para a realização de entrevistas. Contudo, mesmo com essas limitações, o trabalho foi muito importante para o aprendizado. A confiança depositada na proposta do pesquisador facilitou muito sua articulação para com o público. Essa troca de fidelidade torna-se muito rica para o desenvolvimento do trabalho. Acima de tudo, o suporte oferecido pelas pessoas envolvidas nesse processo, faz com que o pesquisador se sinta gratificado por ter seu trabalho reconhecido. 
Contribuições de Design Thinking à humanização do tratamento de câncer infantil

\section{REFERÊNCIAS}

BROWN, Tim. Design Thinking: Uma metodologia poderosa para decretar o fim das velhas ideias. São Paulo: Campus, 2010.

CHOO, Chun Wei. A organização do conhecimento: como as organizações usam a informação para criar significado, construir conhecimento e tomar decisões. São Paulo: Senac São Paulo, 2003.

DEMARCHI, Ana Paula P. Gestão Estratégica de Design com a abordagem de Design Thinking: proposta de um sistema de produção do conhecimento. 2011. Tese (Doutorado em Engenharia e Gestão do Conhecimento) - Universidade Federal de Santa Catarina, Santa Catarina, 2011.

FIRESTONE, Joseph M. e McELROY, Mark. Key Issues in New knowledge management. Burlington: Butterworth-Heinemann, 2003.

GIL, A. C. Como elaborar projetos de pesquisa. 3. ed. São Paulo: Atlas, 1991

HAMMERSLEY, M.; ATKINSON, P. Etnografía: métodos de investigación. Barcelona: Paidós, 1994.

IKEDA, Ana. A.; PEREIRA, Beatriz de Castro Sebastião; GIL, Camila. Etnografia em marketing: uma discussão inicial. REAd, Ed. 52, vol. 12, no 4, jul-ago 2006.

LAKATOS, Eva M. e MARCONI, Marina de A. Técnicas de Pesquisa. São Paulo: Atlas, 1999.

LANGENBACH, Marcos L. Além do apenas funcional: Inovação social e design de serviços na realidade brasileira. 2008. Dissertação (Mestrado em Engenharia de Produção) - Universidade Federal do Rio de Janeiro, Rio de Janeiro, 2008. Disponível em <http://design.org.br/artigos_cientificos/alem_ apenas_funcional.pdf>

LOCKWOOD, Thomas. Design thinking: Integrating innovation, customer experience, and brand value. New York: Allworth Press, 2006.

MANZINI, Ezio. Design para a inovação social e sustentabilidade: comunidades criativas, organizações colaborativas e novas redes projetuais. Rio de Janeiro: E-papers, 2008.

MARTIN, Roger. The design of business: Why design thinking is the next competitive advantage. Boston: Harvard Bussiness Press, 2009.

MCELROY, Mark W. The New Knowledge Management: complexity, learning and Sustainable Innovation. Burlington: Butterworth-Heinemann, 2003.

MORACE, Francesco. Consumo autoral: as gerações como empresas criativas. São Paulo: Estação das Letras e Cores, 2009.

NONAKA, I.; TAKEUCHI, H. Criação de conhecimento na empresa: como as empresas japonesas geram a dinâmica da inovação. Rio de Janeiro: Campus, 1997.

POPPER, Karl Raimund. Conhecimento objetivo: uma abordagem evolucionária. São Paulo: Belo Horizonte, 1975.

SPURRIER, Barbara. Design Thinking, 2012. Disponível em: <http://www.mayo.edu/center-forinnovation/what-we-do/design-thinking> Acessado em Abril. 2012.

Mayo Clinic: Design Thinking in Health Care. In: Yale School of Management, 2012. Disponível em: <http://nexus.som.yale.edu/design-mayo> Acesso em Abril. 2012.

What do we want? Social Design. In: Design 21 Social Design Network, 2012. Disponível em: <http:// 
BELLUCCI, Miguel; MARTINS, Rosane

www.design21sdn.com/design21/about>. Acessado em: Março. 2012.

Health Educators. In: World Wide Breast Cancer, 2012. Disponível em: <http://www.

worldwidebreastcancer.com/health-educators $>$. Acessedo em: Abril. 2012

Particularidades do Câncer Infantil. In: Instituto Nacional do Câncer, 2012. Disponível em: <http:// www.inca.gov.br/conteudo_view.asp?id=343>. Acessedo em: Janeiro. 2012 